\title{
Bad News for Conservatives? Moral Judgments and the Dark Triad Personality Traits: A Correlational Study \\ Marcus Arvan \\ University of Tampa
}

\begin{abstract}
This study examined correlations between moral value judgments on a 17item Moral Intuition Survey (MIS), and participant scores on the Short-D3 "Dark Triad" Personality Inventory - a measure of three related "dark and socially destructive" personality traits: Machiavellianism, Narcissism, and Psychopathy. 567 participants (302 male, 257 female, 2 transgendered; median age 28) were recruited online through Amazon Mechanical Turk and Yale Experiment Month web advertisements. Different responses to MIS items were initially hypothesized to be "conservative" or "liberal" in line with traditional public divides. Our demographic data confirmed all of these hypothesized categorizations. We then tested two broad, exploratory hypotheses: (H1) the hypothesis that there would be "many" significant correlations between conservative MIS judgments and the Dark Triad, and (H2) the hypothesis that there would be no significant correlations between liberal MIS judgments and Machiavellianism or Psychopathy, but "some" significant correlations between liberal MIS judgments and Narcissism. Because our hypotheses were exploratory and we ran a large number of statistical tests (62 total), we utilized a Bonferroni Correction to set a very high threshold for significance $(p=.0008)$. Our results broadly supported our two hypotheses. We found eleven significant correlations between conservative MIS judgments and the Dark Triad - all at significance level of $\mathrm{p}<.00001$ - and no significant correlations between liberal MIS judgments and the Dark Triad. We believe that these results raise provocative moral questions about the personality bases of moral judgments. In particular, we propose that because the Short-D3 measures three "dark and antisocial" personality traits, our results raise some prima facie worries about the moral justification of some conservative moral judgments.
\end{abstract}

\section{Introduction}

Commonsense suggests that there is a relationship between personality traits and moral value judgments. History is particularly suggestive in this regard. Consider, for example, the following historical figures, their personalities, and some of their more notable moral judgments: 
- Adolf Hitler (mass murderer), notable personality trait(s): "counteractive narcism," a type that is stimulated by real or imagined insult or injury (Murray 1938); notable moral judgment(s): anti-semitic.

- Thomas Hobbes (political philosopher), notable personality trait(s): famous for claiming that, "my mother gave birth to twins: myself and fear"; notable moral judgment(s): believed that the purpose of government is to protect people from fear, mutual mistrust, and anarchy (Hobbes 1651).

- Jean-Jacques Rousseau (political philosopher), notable personality trait(s): notoriously vain, ungrateful, and paranoid (Rousseau 1782); notable moral judgment(s): moral and political philosophy focused on inequality and envy (Rousseau 1754, 1762).

- Immanuel Kant (philosopher), notable personality trait(s): famous for living such a strict and predictable life that his neighbors reportedly set their clocks according to his morning walks; notable moral judgment(s): held that morality is fundamentally a matter of rigorous conformity to universal law (Kant 1785).

These are only a few historical cases. Still, they are very suggestive. In each case, the person's moral judgments "fit" their personality. It does not seem entirely surprising that someone like Hitler - someone with a personality disposed to imagine threats or slights would be an anti-Semite. Similarly, it is not surprising that someone like Hobbes - a fearful individual - would construct a moral philosophy based on fear and mistrust; or that an orderly and structured person such as Kant would develop a moral philosophy emphasizing universal law; and so on. It is hard to believe that these are just lucky 
coincidences. Indeed, commonsense tells us that an individual's personality should have some effect on their moral views. However, "commonsense" does not suffice for empirical science. Commonsense claims can turn out to be false. Thus, we should carefully investigate whether any significant relationships exist between personality and moral judgments.

Empirical research on the relationship between personality and moral judgments is still in its relative infancy. Some recent studies indicate that there may be a positive relationship between utilitarian moral judgments and both psychopathic and Machiavellian personality traits (see Glenn et. al 2009; Bartels \& Pizarro [in press]). Another recent study (Wright \& Baril 2011) indicates that "conservatives" are more "threat-sensitive" than liberals, seeing the world as a more dangerous place. Several recent studies also indicate that heritably personality traits predict judgments of moral responsibility (Feltz \& Cokely 2009). Finally, Graham et al. (2009) have shown that liberals and conservatives reason about morality in very different ways, with liberals showing a greater endorsement and use of "harm/care" and "fairness/reciprocity" than other foundations, and conservatives endorsing and using five different moral foundations ("harm/care", "fairness/reciprocity", "ingroup/loyalty", "authority/respect", and "purity/sanctity") much more equally. Although Graham et. al's study does not explicitly focus on personality (again, their focus is on moral reasoning), an individual's reasoning style arguably is an aspect of their personality. ${ }^{1}$ Let us explain what our study stands to add to this rapidly growing body of literature.

\footnotetext{
${ }^{1}$ This is only meant as a prima facie claim. Further research is necessary to determine whether, or to what extent, moral reasoning styles comprise bona fide personality traits.
} 
Our study investigated an issue in personality and moral judgment for which there are, as of yet, no published empirical studies: whether there are significant positive correlations between three "dark and antisocial" personality traits - the so-called "Dark Triad" (Machiavellianism, Narcissism, and Psychopathy) - and moral judgments across an array of social and political issues, including economic justice, gay marriage, gun control, and capital punishment (for more on the Dark Triad, see e.g. Paulhus \& Williams 2002 and Jones and Paulhus 2010a). Although behaviors associated with the Dark Triad have been studied in detail (see e.g., Jones and Pauhus 2010b; Jones and Paulhus [in press]; and Nathanson et al. 2006), there are no published studies to date focusing on the relationship between the Dark Triad and specific moral judgments. We were interested in the Dark Triad because of their "morally questionable" nature. Although, as we explain in $\S 4$, it is a complex empirical and philosophical question whether, and to what extent, these three traits are in fact morally undesirable, all three traits are, at the very least, morally worrisome. Machiavellianism, after all, is a tendency to deceive and manipulate (Paulhus and Williams 2002; Gunnthorsdottir et al. 2002); narcissism a tendency to vanity, conceit, selfishness, feelings of entitlement, difficulty with empathy, and lack of guilt or remorse (Thomas 2010); and psychopathy tendencies to impulsesiveness, irresponsibility, and lack of foresight, guilt, remorse, and normal empathy (Semple 2005: 448-9). Our aim was merely to see whether these three traits correlate positively with traditionally conservative or liberal judgments on different moral issues, and if so, what further empirical and philosophical questions such findings might raise. 


\section{Methods}

\subsection{Subjects}

567 participants (302 male, 257 female, 2 transgendered; median age 28) were recruited online through Mechanical Turk and Yale Experiment Month web advertisements (whereupon clicking a further link, volunteers were randomly enrolled in any one of several dozen different experiments). Mechanical Turk participants were rewarded for their participation with a small monetary compensation (\$0.50). Yale Experiment Month website participants were uncompensated. IRB approval was obtained for research on human subjects, informed consent was obtained from all participants, and all relevant laws and other institutional guidelines were followed.

\subsection{Design, Materials, and Procedure}

Participants were presented with three surveys: the 27-item "Short-D3" Dark Triad survey (Jones \& Paulhus 2010a), a 17-item Moral Intuition Survey (MIS), and a demographic survey [see appendix for all three surveys].

The Short-D3 is a 27-question personality inventory which asks respondents to respond to questions on a $1-5$ scale (where ' 1 '=disagree strongly, ' 3 '=neither agree nor disagree, and '5'=agree strongly). The Short-D3's construct for Machiavellianism is the mean response to items 1-9 (with item 2 reverse-scored). Its construct for Narcissism is the mean response to items 10-18 (with items 11 and 16 reverse-scored). Finally, the Psychopathy construct is the mean response to items 19-27 (with items 20 and 26 reversescored). The Short-D3 has been demonstrated to be a valid measure of all three Dark Triad traits (see Jones \& Paulhus 2010a). 
The Moral Intuition Survey (MIS) is a 17-question survey which asks respondents to morally judge individual moral propositions on a range of 5 response levels (where ' 1 '=morally wrong, ' 3 '=morally neutral (neither good nor bad), and ' 5 '=morally required). It is important to clarify that we did not analyse individual respondent's collective responses to all items as an indicator of a particular type of moral characteristic or trait of that respondent. We only analysed the responses of the sample population to each MIS question separately. That is we treated each question as a (singular) Likert item with a 1-5 range in response levels to be analysed individually and not as an item in a Likert scale to be analysed collectively. Let us explain. Particular distibutions of an individual's answers to a battery of questions (the responses to the battery constituting a Likert scale) can be taken to represent a particular psychometric property of the individual. For example, the responses to several items on a personality inventory (e.g. the Short-D3) may be summed as a representation of a particular personality trait (e.g. Psychopathy). The MIS was not intended to measure any such property summed across different items in the survey. Instead, it was intended to measure judgments in a population about particular moral issues represented by a single question. Consider, for example, MIS item\#10 ("Gay marriage is: "). We were only interested in measuring how respondents in the population judged that particular issue (e.g. the morality of gay marriage), considered in isolation, and not to relate the way they made judgements on all issues to any personality traits. We therefore believe that this decision-to treat each question in the survey as a a Likert item rather than as an item in a Likert scale-is clearly justified, given our study's aims. Finally, we hold that the MIS's 1-5 scale is perspicuous in what it purports to measure. A person who gives a response of "1" to MIS item\#10 ("Gay marriage is: ") is simply reporting their 
judgement that gay marriage is morally wrong. Although there are deep philosophical and linguistic questions about the meaning of moral terms (e.g. "morally wrong"), we do not believe it possible or advisable to attempt to resolve these issues in our study. Questions about the MIS's 1-5 scale can also be addressed in terms of the survey's validity, which we now discuss.

Although the MIS is an untested survey, it not only has very strong face validity (intuitively measuring exactly what it is appears to measure: moral judgments about what is good, bad, right, and wrong); our results also demonstrate that it has strong external validity. All of our classificatory hypotheses heading into the study, which categorized different MIS judgments as either "liberal" or "conservative" (see §2.4.1) - were strongly confirmed by our demographic results (§3.1.) at a significance of $p<.00001$. These are strong indications of external validity. They indicate that the MIS measures precisely what we expected: traditional liberal and conservative moral judgments on each item covered by the MIS. Internal validity is not an issue for our study, as we do not purport to investigate causation.

Finally, the demographic survey contained a number of customary items (selfreported age, race, marital status), but also items on political party affiliation (US citizens only), social and economic leanings on a 1-7 scale (where '1'=conservative, '4'=moderate, and ' 7 '=liberal), and religious leanings, also on a 1-7 scale (where ' 1 '=very religious, '4'=uncommitted, and '7'=anti-religious/atheist). 


\subsection{Hypotheses}

\subsubsection{Classificatory Hypotheses}

Responses to each MIS item were identified in advance as either "conservative" or "liberal," in line with traditional public divides on each issue. Higher scores (i.e. '4' or ' 5 ') on the following MIS items were identified as economically liberal:

MIS Item\#1: "A government ought to tax its citizens in order to ensure that all citizens enjoy basic life necessities (example: Social Security, which provides oldage/retirement benefits, and temporary assistance for needy families, such as food stamps etc.)."

MIS Item\#2: "A government ought to tax its citizens in order to provide financial aid (i.e. "welfare") to the poor and unemployed."

MIS Item\#3: "A government ought to tax its citizens in order to bring about a more equal or "fair" distribution of wealth."

MIS Item\#11: "Affirmative action is: "

Lower scores (i.e. ' 1 ' or ' 2 ') on these same items were identified as economically conservative. Next, higher scores on the following item were identified as economically conservative, and lower scores as economically liberal:

MIS Item\#8: "A government ought to never intervene in free economic markets except to prevent or punish force (theft, murder) or fraud (breaking contracts)."

Next, higher scores on the following MIS items were identified as socially liberal, and lower scores as socially conservative:

MIS Item\#6: "The government has a duty to conform to United Nations resolutions." MIS Item\#10: "Gay marriage is: “

MIS Item\#12: "Gun control is: “

Finally, lower scores on the following MIS items were identified as socially liberal and higher score as socially conservative: 
MIS Item\#4: “A government ought to restrict citizens' liberties somewhat in order to protect them from terrorist attacks."

MIS Item\#5: "A government ought to detain suspected terrorists as long as necessary, without trial, in order to prevent terrorist attacks."

MIS Item\#7: "The government has the right to wage war on enemy states even if doing so violates United Nations resolutions."

MIS Item\#14: "The death penalty for persons convicted of premeditated murder is: "

Finally, we did not identify responses to the following items as either liberal or conservative, as in our judgment there are no "traditional" liberal or conservative answers to these items:

MIS Item\#13: "Selfishness is: “

MIS Item\#15: "Someone you know asks you an important question that you cannot avoid answering. If you tell the truth, it will cause a number of people significant unhappiness. If you lie, no one will ever find out, and everyone will be happy. Telling the lie is: “

MIS Item\#16: "A trolley is running out of control down a track. If it continues on its current path, it will run over and kill five innocent people. If you flip a switch, the trolley will run down a different track, killing only one innocent person. Flipping the switch is: "

MIS Item\#17: "A trolley is running out of control down a track. If it continues on its current path, it will run over and kill five innocent people. You are on a bridge above the trolley, and there is a very fat man next to you, who you could push in front of the trolley saving the five people. However, the fat man will die. Pushing the fat man is: "

\subsubsection{Primary Hypotheses}

Because of the exploratory nature of our study and the relative paucity of existing empirical research on the liberal/conservative divide and "dark" personality traits, we began the study with two very broad and exploratory primary hypotheses, which we based on a couple of popular public stereotypes about liberals and conservatives. Both of our 
hypotheses were documented prior to running the study in our application supplied to the Experiment Month Initiative. Our first hypothesis, (H1), was based on the common stereotype that conservatives are "hard-hearted" or callous (a stereotype that is often identified in political discourse with conservatives' focus on free markets, antipathy toward social programs for the poor [e.g. Welfare], and perceived nationalism with respect to war, terrorism, etc.). Due to this stereotype, our first hypothesis (H1) was that there would be "many" significant positive correlations between conservative moral judgments and all three Short D3 constructs. Our second hypothesis, (H2), was based on the common stereotype that liberals are (a) "bleeding heart" altruists (a stereotype sometimes said to be reinforced by liberals' support of social programs for the poor [e.g. Welfare], affirmative action, rights for gays/lesbians/transgendered individuals, etc.), but also (b) self-righteous "meddlers" who think they know what is best for others. Due to this (two-part) stereotype, our second hypothesis (H2) was that there would be no significant positive correlations between liberal response-types and Machiallianism or Psychopathy, but "some" significant positive correlations between liberal response-types and Narcissism.

We admit that our two hypotheses are extremely broad and exploratory in nature. There was, in our judgment, simply not enough sound empirical data on the Dark Triad and moral judgments to warrant more precise hypotheses than the exploratory ones we chose. In order to compensate for the vague and exploratory nature of our hypotheses, we utilized a Bonferroni Correction in our statistical analyses, setting a very high significance threshold ( $p=.0008)$, to ensure that our results are genuine. The fact that all of our significant results (see §3) were significant at far higher threshold than even this (all 
significant observations were significant at $p<.00001$ ) should also dispel worries about whether our results are genuine.

\subsection{Statistical Methods}

Because of the exploratory nature of our study and the high number of correlation tests we ran (62), we utilized a Bonferroni Correction, setting our threshold for significance at $p=.0008$.

\section{Results}

\subsection{Results for Classificatory Hypotheses}

Our data strongly confirmed each of our classificatory hypotheses. As Tables I and II illustrate (see below), all of our classificatory hypotheses were confirmed well beyond our Bonferroni-Corrected significance threshold of $\mathrm{p}=.0008$ (all were confirmed at $p<.00001$ ).

TABLE I. Results for Hypothesized Classifications of "Economic" Judgments

\begin{tabular}{|l|c|}
\hline MIS Survey Item & $\begin{array}{l}\text { "I consider myself to be a: [select from scale 1-7, where } \\
\text { 1=fiscal/economic conservative, 4=fiscal/economic moderate, } \\
\text { 7=fiscal/economic liberal]" }\end{array}$ \\
\hline $\begin{array}{l}\text { Item\#1: "A government ought to tax its } \\
\text { citizens in order to ensure that all citizens } \\
\text { enjoy basic life necessities..." }\end{array}$ & $\begin{array}{c}r=.362^{* *} \\
p=<.00001 \\
\text { (confirms hypothesis) }\end{array}$ \\
\hline $\begin{array}{l}\text { Item\#2: "A government ought to tax its } \\
\text { citizens in order to provide financial aid (i.e. } \\
\text { "welfare") to the poor..." }\end{array}$ & $\begin{array}{c}r=.394^{* *} \\
p=<.00001\end{array}$ \\
(confirms hypothesis)
\end{tabular}

${ }^{* *}$ Correlation is significant at the $<.00001$ level (2-tailed). 


\section{TABLE II. Results for Hypothesized Categorizations of "Social" Judgments}

\begin{tabular}{|c|c|}
\hline MIS Survey Item & $\begin{array}{l}\text { "I consider myself to be a: [select from scale } 1-7 \text {, where } 1=\text { social } \\
\text { conservative, } 4=\text { social moderate, } 7=\text { social liberal]" }\end{array}$ \\
\hline $\begin{array}{l}\text { Item\#4: "A government ought to restrict } \\
\text { citizens" liberties somewhat in order to } \\
\text { protect them from terrorist attacks." }\end{array}$ & $\begin{array}{c}r=-.166^{* *} \\
p=<.00001 \\
\text { (confirms hypothesis) }\end{array}$ \\
\hline $\begin{array}{l}\text { Item\#5: "A government ought to detain } \\
\text { suspected terrorists as long as necessary } \\
\text { without trial to prevent terrorist attacks." }\end{array}$ & $\begin{array}{c}\mathrm{r}=-.301^{* *} \\
\mathrm{p}=<.00001 \\
\text { (confirms hypothesis) }\end{array}$ \\
\hline $\begin{array}{l}\text { Item \#6: "The government has a duty to } \\
\text { conform to United Nations resolutions." }\end{array}$ & $\begin{array}{c}r=.156^{* *} \\
p=<.00001 \\
\text { (confirms hypothesis) }\end{array}$ \\
\hline Item\#9: "Homosexual behavior is: “ & $\begin{array}{l}r=.399^{* *}, p=<.00001 \\
\text { (confirms hypothesis) }\end{array}$ \\
\hline Item\#10: "Gay marriage is: “ & $\begin{array}{l}r=.426^{* *}, p=<.00001 \\
\text { (confirms hypothesis) }\end{array}$ \\
\hline Item\#12: "Gun control is: “ & $\begin{array}{l}r=.232^{* *}, p=<.00001 \\
\text { (confirms hypothesis) }\end{array}$ \\
\hline $\begin{array}{l}\text { Item\#14: "The death penalty for persons } \\
\text { convicted of premeditated murder is: "“ }\end{array}$ & $\begin{array}{l}r=-.283^{* *}, p=<.00001 \\
\text { (confirms hypothesis) }\end{array}$ \\
\hline
\end{tabular}

${ }^{* *}$ Correlation is significant at the $<.00001$ level (2-tailed).

\subsection{Results for "Economic" Moral Judgments}

Our results for MIS items pertaining to economic moral issues - e.g. moral judgments about Welfare, Social Security, free markets, and economic equality - are presented in Table III (see below). These results cohere weakly with our first exploratory hypothesis, (H1) - the hypothesis that there would be "many" correlations between Short D3 constructs and "conservative" response-type - as we only found two significant positive correlations between conservative response-types and Short-D3 constructs. The two significant positive correlations we did observe, however - correlations between conservative responses to MIS item\#8 (i.e. governments should never intervene in free economic markets) and both Machiavellianism and Narcissism - were significant at a very high level 
$(p<.00001)$. Although both of these correlations cohere with (H1), there were far fewer significant correlations between conservative response-types and the Short-D3 than the "many" we expected.

Our results are also mostly consistent with our second exploratory hypothesis, (H2): the hypothesis that there would be no positive correlations between liberal response-types and Machiavellianism or Psychopathy, but perhaps "some" correlations between liberal response-types and Narcissism. Our results indicated no significant correlations between liberal responses and any of the three Short-D3 constructs.

Table III. Short D3 Correlations for Economic Moral Judgments

\begin{tabular}{|l|c|c|c|}
\hline \multicolumn{1}{|c|}{ MIS Items } & MACHIAVELLIANISM & NARCISSISM & PSYCHOPATHY \\
\hline $\begin{array}{l}\text { Item\#1: "A government ought } \\
\text { to tax its citizens in order to } \\
\text { ensure that all citizens enjoy } \\
\text { basic life necessities..." }\end{array}$ & $r=.052, p=.218$ & $r=-.009, p=.824$ & $R=-.125, p=.003$ \\
\hline $\begin{array}{l}\text { Item\#2: "A government ought } \\
\text { to tax its citizens in order to } \\
\text { provide financial aid (i.e. } \\
\text { "welfare") to the poor..." }\end{array}$ & $r=.026, p=.534$ & $r=.013, p=.757$ & $R=-.052, p=.224$ \\
\hline $\begin{array}{l}\text { Item\#3: "A government ought } \\
\text { to tax its citizens in order to } \\
\text { bring about a more equal or } \\
\text { "fair" distribution of wealth." }\end{array}$ & $r=-.052, p=.215$ & $r=.033, p=.435$ & $R=-.028, p=.506$ \\
\hline $\begin{array}{l}\text { Item\#8: Government ought to } \\
\text { never intervene in free } \\
\text { economic markets except to } \\
\text { prevent or punish force (theft, } \\
\text { murder) or fraud." }\end{array}$ & $\begin{array}{c}r=.216^{* *} \\
\text { conserrelation with } \\
\text { conservative judgment) }\end{array}$ & $\begin{array}{c}r=.150^{* *}, p= \\
<.00001 \\
\text { (correlation with } \\
\text { conservative judgment) }\end{array}$ & $\begin{array}{c}r=.116, p=.006 \\
\text { conserrelation with }\end{array}$ \\
\hline $\begin{array}{l}\text { Item\#11: "Affirmative Action } \\
\text { is: “" }\end{array}$ & $r=.000, p=.994$ & $r=.011, p=.798$ & $R=-.039, p=.358$ \\
\hline
\end{tabular}

${ }^{* *}$ Correlation is significant at the $<.00001$ level (2-tailed).

\subsection{Results for "Social” Judgments}

Our results for the MIS items pertaining to "social issues" - e.g. gay marriage, homosexuality, capital punishment, etc. - are reported in Table IV (see below). These results cohere much more strongly with our first hypothesis (H1) than "economic" 
judgments. Nine significant positive correlations were observed between Short-D3 constructs and conservative judgment-types on social issues, all at a very high level of significance $(p<.00001)$. These correlations are also notable in their groupings. Conservative response-types to MIS items \#5 (detention of suspected terrorists indefinitely without trial) and MIS \#14 (capital punishment) both correlated significantly (at $p<.00001$ ) with all three Short-D3 constructs (Machiavellianism, Narcissism, and Psychopathy). Similarly, conservative response-types to MIS item \#7 ("the government has a right to wage war in violation of UN resolutions") correlated significantly (at $p<.00001$ ) with both Narcissism and Psychopathy (but not Machiavellianism - though its result here was somewhat close to our significance threshold, at $p=.009$ ). Finally, conservative responsetypes to MIS item \#10 ("Gay Marriage is: ") correlated significantly with Psychopathy (at $p<.00001)$.

Our results on "social judgments" also cohered very well (but not perfectly) with our second hypothesis, (H2). No significant correlations were observed between Short D3 constructs and liberal response-types. 


\section{Table IV. Short D3 Correlations for “Social” Judgments}

\begin{tabular}{|c|c|c|c|}
\hline MIS Item & MACHIAVELLIANISM & NARCISSISM & PSYCHOPATHY \\
\hline $\begin{array}{l}\text { Item\#4: "A government ought } \\
\text { to restrict citizens' liberties } \\
\text { somewhat in order to protect } \\
\text { them from terrorist attacks." }\end{array}$ & $r=.101, p=.017$ & $r=.137, p=.001$ & $r=.089, p=.037$ \\
\hline $\begin{array}{l}\text { Item\#5: "A government ought } \\
\text { to detain suspected terrorists as } \\
\text { long as necessary without trial } \\
\text { to prevent terrorist attacks." }\end{array}$ & $\begin{array}{c}r=.267^{* *}, \\
p=<.00001 \\
\text { (correlation with } \\
\text { conservative judgment) }\end{array}$ & $\begin{array}{c}r=.255^{* *}, \\
p=<.00001 \\
\text { (correlation with } \\
\text { conservative judgment) }\end{array}$ & $\begin{array}{c}r=.202^{* *}, \\
p=<.00001 \\
\text { (correlation with } \\
\text { conservative judgment) }\end{array}$ \\
\hline $\begin{array}{l}\text { Item\#6: "The government has } \\
\text { a duty to conform to United } \\
\text { Nations resolutions." }\end{array}$ & $r=.067, p=.116$ & $r=.054, p=.200$ & $r=-.003, p=.944$ \\
\hline $\begin{array}{l}\text { Item\#7: "The government has } \\
\text { the right to wage war on } \\
\text { enemy states even if doing so } \\
\text { violates UN resolutions." }\end{array}$ & $\begin{array}{c}r=.110, p=.009 \\
\text { (correlation with } \\
\text { conservative judgment) }\end{array}$ & $\begin{array}{c}r=.153^{* *}, \\
p=<.00001 \\
\text { (correlation with } \\
\text { conservative judgment) }\end{array}$ & $\begin{array}{c}r=.271^{* *} \\
p=<.00001 \\
\text { (correlation with } \\
\text { conservative judgment) }\end{array}$ \\
\hline $\begin{array}{l}\text { Item\#9: "Homosexual } \\
\text { behavior is: “ }\end{array}$ & $r=-.054, p=.201$ & $r=-.066, p=.120$ & $r=.-077, p=.070$ \\
\hline Item\#10: "Gay marriage is: “ & $r=-.075, p=.076$ & $r=-.078, p=.065$ & $\begin{array}{c}r=-.155^{* *}, \\
p=<.00001 \\
\text { (correlation with } \\
\text { conservative judgment) }\end{array}$ \\
\hline Item\#12: "Gun control is: “ & $r=-.025, p=.562$ & $r=-.081, p=.055$ & $r=-.117, p=.006$ \\
\hline $\begin{array}{l}\text { Item\#14: "The death penalty } \\
\text { for persons convicted of } \\
\text { premeditated murder is: " }\end{array}$ & $\begin{array}{c}r=.299^{* *}, \\
p=<.00001 \\
\text { (correlation with } \\
\text { conservative judgment) }\end{array}$ & $\begin{array}{c}r=.156^{* *} \\
p=<.00001 \\
\text { (correlation with } \\
\text { conservative judgment) }\end{array}$ & $\begin{array}{c}r=.189^{* *} \\
p=<.00001 \\
\text { (correlation with } \\
\text { conservative judgment) }\end{array}$ \\
\hline
\end{tabular}

${ }^{* *}$ Correlation is significant at the $<.00001$ level (2-tailed).

\subsection{Results for Uncategorized Items}

Finally, Table V reports our results for the MIS items (items 13 and 15-17) - the items for which we did not have any pre-hoc hypotheses. First, we found a significant positive correlation between Psychopathy and the judgment that "selfishness" is morally good or morally required (MIS item\#13). Second, we found a significant positive correlation between the (utilitarian) judgment that it is good or right to lie for the greater good (MIS 
item\#15) and Machiavellianism. Third, we found significant positive correlations between both Machiavellianism and Psychopathy and the moral judgment that it is good or required to "push the fat man" in front of a trolley to save five people (the so-called "footbridge trolley case" - see Thompson 1976 and Greene 2007).

Table V. Short D3 Correlations for Uncategorized MIS Items

\begin{tabular}{|c|c|c|c|}
\hline MIS Items & MACHIAVELLIANISM & NARCISSISM & PSYCHOPATHY \\
\hline Item\#13: "Selfishness is:" & $r=.015, p=.720$ & $r=.039, p=.363$ & $\begin{aligned} r & =.150^{* *} \\
p & =<.00001\end{aligned}$ \\
\hline $\begin{array}{l}\text { Item\#15: "Someone you know } \\
\text { asks you an important question } \\
\text { that you cannot avoid } \\
\text { answering. If you tell the } \\
\text { truth, it will cause a number of } \\
\text { people significant } \\
\text { unhappiness. If you lie, no } \\
\text { one will ever find out, and } \\
\text { everyone will be happy. } \\
\text { Telling the lie is:" }\end{array}$ & $\begin{aligned} r & =.204^{* *}, \\
p & =<.00001\end{aligned}$ & $r=.103, p=.015$ & $r=.079, p=.063$ \\
\hline $\begin{array}{l}\text { Item\#16: "A trolley is running } \\
\text { out of control down a track. If } \\
\text { it continues on its current path, } \\
\text { it will run over and kill five } \\
\text { innocent people. If you flip a } \\
\text { switch, the trolley will run } \\
\text { down a different track, killing } \\
\text { only one innocent person. } \\
\text { Flipping the switch is: " }\end{array}$ & $r=.096, p=.215$ & $r=.074, p=.082$ & $r=.053, p=.213$ \\
\hline $\begin{array}{l}\text { Item\#17 (footbridge case): A } \\
\text { trolley is running out of } \\
\text { control down a track. If it } \\
\text { continues on its current path, it } \\
\text { will run over and kill five } \\
\text { innocent people. You are on a } \\
\text { bridge above the trolley, and } \\
\text { there is a very fat man next to } \\
\text { you, who you could push in } \\
\text { front of the trolley saving the } \\
\text { five people. However, the fat } \\
\text { man will die. Pushing the fat } \\
\text { man is.." }\end{array}$ & $\begin{array}{c}r=.191^{* *} \\
p=<.00001\end{array}$ & $\begin{array}{l}r=.121, \\
p=.004\end{array}$ & $\begin{array}{c}r=.231^{* *} \\
p=<.00001\end{array}$ \\
\hline
\end{tabular}

${ }^{* *}$ Correlation is significant at the $<.00001$ level (2-tailed). 


\section{Discussion}

Although our study was exploratory, all of our significant results are provocative and significant at a very high threshold $(\mathrm{p}<.00001)$. Our results thus indicate that there are significant positive correlational relationships between the Dark Triad traits and conservative judgments on the following issues: (a) capital punishment, (b) indefinite detention of suspected terrorists without trial, (c) the right of a government to wage war in violation of UN resolutions, (d) the view that government should never intervene in free markets except to prevent force and fraud, and (e) gay marriage. Second, our results indicate that Machiavellianism has a positive relationship to the (utilitarian) judgment that it is morally good or right to lie for the greater good. Finally, our results add additional support to recent findings that Machiavellianism and Psychopathy correlate with positive moral judgments in the "footbridge" trolley case (Bartels \& Pizarro [in press]). It is worth noting that we found far more significant relationships between "dark" personality traits and particular moral judgments when studying social moral judgments rather than economic moral judgments. Although we only studied a limited number of social and economic moral judgments, our results broadly suggest that conservative social judgments may bear a stronger relationship to the Dark Triad than conservative economic judgments or liberal judgments (for which, again, no Dark Triad correlations were found). Further research on the Dark Triad and conservative/liberal divides is necessary to determine whether this is the case.

We believe that our results are not only valid but also provocative, raising many questions worthy of further research. Let us briefly discuss some possible avenues for empirical and philosophical research. First, and most obviously, our results suggest the 
importance of performing more empirical research on the relationship of moral judgments and personality. We found several statistically significant relationships between the Dark Triad and moral judgments in the case of twelve moral issues that we chose more or less arbitrarily. As such, it is likely that significant correlations exist between the Dark Triad and judgments on other moral issues. Our study thus justifies further empirical research in these areas. Second, our study also raises provocative moral questions worthy of further philosophical research. In particular, our results raise interesting questions about moral epistemology (i.e. how moral propositions are apprehended, known, justified, etc.). We believe that if our results are conjoined with an influential approach to virtue ethics (Hursthouse 1999) or a kind of "virtue epistemology", some kinds of ad hominem arguments may be inductively strong (contrary to received wisdom). Let us explain.

Ad hominem arguments (arguments that criticize a judgment or belief on the basis of the person who holds them) are generally recognized to be fallacious. The fact that a person is "bad" is not, in general, a sufficient reason to think that their beliefs are false. However, ad hominem arguments are not obviously fallacious in moral philosophy. Quite the contrary, there is a long history in "virtue ethics" (which stems back at least to Plato and Aristotle) that involves criticizing moral views on the basis of a person's personality or "soul" (see Plato's Republic 419-421c, 436b-445b and Aristotle's Nichomachean Ethics). Furthermore, contemporary approaches to virtue ethics also appear capable (at least in principle) of justifying certain ad hominem arguments. For example, Rosalind Hursthouse (1999, p. 28), a well-known virtue-ethicist, argues that we should understand morally right action in terms of what the virtuous person would choose. If this is a correct definition of morally right action, then some ad hominem arguments could indeed be inductively strong. 
Here is a hypothetical example. Suppose we knew (A) that people like Hitler are not morally virtuous individuals (a safe assumption), and we empirically demonstrated that (B) it is typically people like Hitler (i.e. "counteractive narcissists") who find anti-semitic or racist moral views attractive. If both of these things were the case and Hursthouse's definition of right action is correct, then we would have strong inductive grounds for rejecting anti-semitic and racist views on the basis of the personality traits to which they are empirically linked.

While Hursthouse's definition of right action is still a matter of philosophical debate, the argumentative strategy we suggest (i.e. using empirical evidence on personality and moral judgments to justify some types of ad hominem arguments) need not rely on her analysis. Such a strategy might also be justified by a virtue epistemology, such as Zagzebski's (1996) analysis of epistemic virtue. Our purpose is not to defend or elaborate on either of these theories, but simply to point out how existing philosophical research projects might be fruitfully (and provocatively) conjoined with our results. Let us explain.

Machiavellianism, narcissism, and psychopathy are all, on their face, "morally worrisome" traits. Again, Machiavellianism is a tendency to deceive and manipulate (Paulhus and Williams 2002; Gunnthorsdottir et al. 2002); narcissism a tendency to vanity, conceit, selfishness, feelings of entitlement, difficulty with empathy, and lack of guilt or remorse (Thomas 2010); and psychopathy indicates tendencies to impulsesiveness, irresponsibility, and lack of foresight, guilt, remorse, and normal empathy (Semple 2005: 448-9). Indeed, people are frequently criticized for having these traits in ordinary life. We say things like, "You can't trust him. He's a psychopath", and, "You can't depend on her. She's a narcissist, and only cares about herself" - and, although the term 19 
"Machiavellianism" is uncommon, we of course do say things like, "Watch your back - he's a manipulator, and a liar." Finally, research indicates that, "To varying degrees, all three constructs entail a dark, socially destructive character with behavior tendencies such as grandiosity, emotional coldness, manipulation and aggressiveness." (Jones and Paulhus 2010). Although the Short D3 does not distinguish between clinically significant and clinically insignificant levels of these three traits (see ibid; a person can, of course, be somewhat narcissistic, Machiavellian, or psychopathic and yet not have a mental disorder, e.g. Narcissistic Personality Disorder or Psychopathy), we tend to believe that all three traits are morally questionable even at a subclinical level. Indeed, in ordinary life, we tend not to admire even sub-clinical Machiavellians, narcissists, or psychopaths. We do not favorably view people who have even mild to moderate tendencies to deceive and manipulate (Machiavellianism); tendencies to grandeur, vanity, conceit, selfishness, and entitlement (narcissism); or tendencies to impulsiveness, irresponsibility, lack of foresight, difficulty with empathy, etc. (psychopathy).

Now, to be clear, our study does not show that these traits are in fact morally bad, or even that particular levels of them are morally bad. While it is difficult to imagine a context in which mild to moderate levels of psychopathy or machiavellianism could be seen as positive, mild to moderate levels of narcissism may in some cases be a morally positive trait (given that a somewhat inflated sense of self can steel people against criticism and lead people to persevere in the face of long odds). ${ }^{2}$ We cannot settle these questions here. Our claim is simply that because the Dark Triad traits are clearly morally disturbing at least on their face, our study motivates (A) further empirical research on the relationship between

\footnotetext{
${ }^{2}$ We thank an anonymous reviewer for pressing this point.
} 
those traits and moral judgments, and (B) further philosophical research to see if results like ours can be profitably conjoined with either a virtue-theoretic analysis of right action or a virtue epistemology in a way that might justify certain kinds of ad hominem arguments.

Finally, some readers might worry that because our study does not address causation, our results are insufficient to motivate our proposal (of using our results to justify ad hominem arguments). After all, our proposal is that moral judgments might be legitimately criticized as based in morally bad traits (a claim that suggests causal dependence). We have several points in reply. First, we agree that further experimental research is necessary to examine causation. Second, we believe that our results indicate causation to be likely, as there are no obvious external variables that might account for the significant correlations we observed. Finally, we believe that if causation does exist, our ad hominem proposal does not depend on a particular direction of causation. For suppose, on the one hand, that the Dark Triad traits cause people to make particular moral judgments. Causation in this direction raises obvious prima facie moral questions (how good is the moral judgment if it is partly based on a morally disturbing trait?). Now suppose that the causal relation is in the opposite direction: that making certain moral judgments (e.g. about the death penalty) causes people to come to have Dark Triad traits. This also seems to us to raise serious prima facie moral questions (namely, how good can a moral judgment be if it causes people to develop disturbing traits?).

To conclude, although the scope of our study is limited, we believe that its results are significant, provocative, and raise a number of important questions worthy of further empirical and philosophical research. 


\section{Acknowledgements}

This study was conducted by Yale Cognitive Science as a part of the Yale Experiment Month initiative, a program financially sponsored by the American Philosophical Association for the purpose of encouraging experimental research by philosophers. The author(s) would like to thank Joshua Knobe, Mark Phelan, Adam Feltz, and the Experiment Month staff for their support and assistance. The author(s) would also to thank an anonymous reviewer from Neuroethics for their very helpful comments. 


\section{References}

Bartels, Daniel M. and Pizarro, David A. (in press). The Mismeasure of Morals: Antisocial Personality Traits Predict Utilitarian Responses to Moral Dilemmas. Cognition.

Feltz, A., \& Cokely, E.T. (2009). Do judgments about freedom and responsibility depend on who you are? Personality differences in intuitions about compatibilism and incompatibilism. Consciousness and Cognition, 18, 342-350

Graham, J., Haidt, J., \& Nosek, B. (2009). Liberals and conservatives use different sets of moral foundations. Journal of Personality and Social Psychology, 96, 1029-1046.

Glenn AL, Raine A, Schug RA. (2009). The neural correlates of moral decision-making in psychopathy. Molecular Psychiatry;14:5-6

Greene, J. D. (2007). The secret joke of Kant's soul, in Moral Psychology, Vol. 3: The Neuroscience of Morality: Emotion, Disease, and Development, W. Sinnott-Armstrong, Ed., MIT Press, Cambridge, MA

Gunnthorsdottir, A., McCabe, K. \& Smith, V. (2002). "Using the Machiavellianism instrument to predict trustworthiness in a bargaining game". Journal of Economic Psychology 23, 49-66. 
Hare, R. D. (2003). The Psychopathy Checklist-Revised, 2nd Edition. Toronto: Multi-Health Systems.

Hobbes, Thomas (1651). Leviathan, or the Matter, Forme, and Power of a Commonwealth, Ecclesiasticall and Civil.

Jones, D.N., \& Paulhus, D.L. (in press). The role of impulsivity in the Dark Triad of personality. Personality and Individual Differences.

Jones, D.N., \& Paulhus, D.L. (2010a). Differentiating the Dark Triad within the interpersonal circumplex. In L.M. Horowitz \& S.N. Strack (Eds.), Handbook of interpersonal theory and research(pp. 249-267). New York: Guilford.

Jones, D.N. \& Paulhus, DL (2010b). Different Provocations Trigger Aggression in Narcissists and Psychopaths. Social and Personality Psychology Science, 1: 12-18.

Kant, Immanuel (1785). Groundwork of the Metaphysics of Morals.

Murray, Henry A. (1938). Analysis of the Personality of Adolf Hitler (Oxford Press).

Nathanson, C., Paulhus, D.L., \& Williams, K.M. (2006). Personality and misconduct correlates of body modification and other cultural deviance markers. Journal of Research in Personality, 40: 779-802. 
Paulhus, D.L., \& Williams, K. (2002). The Dark Triad of personality: Narcissism, Machiavellianism, and psychopathy. Journal of Research in Personality, 36, 556-568.

Rousseau, Jean-Jacques (1782). Confessions of Jean-Jacques Rousseau.

Rousseau, Jean-Jacques (1762). The Social Contract, or Principles of Political Right.

Rousseau, Jean-Jacques (1754). Discourse on the Origin and Basis of Inequality Among Men.

Semple, David (2005). The Oxford Handbook of Psychiatry. USA: Oxford University Press.

Thomas, David (2010). Narcissism: Behind the Mask. (Book Guild Ltd.).

Thomson, Judith Jarvis (1976). "Killing, Letting Die, and the Trolley Problem", The Monist, 59: 204-17.

Wright, J.C. \& Baril, G. (2011). The Role of Cognitive Resources in Determining Our Moral Intuitions: Are we all liberals at heart? Journal of Experimental Social Psychology, 47: 10071012.

Zagzebski, L., (1996). Virtues of the Mind, Cambridge: Cambridge University Press. 


\section{APPENDIX}

\section{Short D3 Personality Inventory}

Directions: Please rate the degree to which you agree with the following statements. You can be honest because your name will not be attached to the answers.

\begin{tabular}{llccc}
\hline Disagree & Disagree & Neither agree & Agree & Agree \\
Strongly & a little & nor disagree & a little & Strongly \\
1 & 2 & 3 & 4 & 5 \\
\hline
\end{tabular}

1. It's not wise to tell your secrets.

2. Most people who get ahead in the world lead clean moral lives.

3. Generally speaking, people won't work hard unless they have to.

4. There's a sucker born every minute.

5. Whatever it takes, you must get the important people on your side.

6. Careful what you say because you never know who may be useful in the future.

7. It's wise to keep track of information that you can use against people later.

8. You should wait for the right time to get back at people.

9. There are things you should not tell people because they don't need to know.

10. People see me as a leader.

11. I hate being the center of attention.

12. Many group activities tend to be dull without me.

13. I know that I am special because everyone keeps telling me so.

14. Those with talent and good looks should not hide them.

15. I like to get acquainted with important people.

16. I feel embarrassed if someone compliments me.

17. I have been compared to famous people.

18. I am likely to show off if I get the chance.

19. I like to get revenge on authorities.

20. I avoid dangerous situations.

21. I am a thrill seeker.

22. Payback needs to be quick and nasty.

23. People often say I'm out of control.

24. It's true that I can be cruel.

25. People who mess with me always regret it.

26. I have never gotten into trouble with the law.

27. I like to pick on losers.

SHORT D3 SCORING

Items 2, 11, 16, 20, and 26 should be reverse scored. Then calculate the mean of the items within each subscale: Machiavellianism (items 1-9); Narcissism (items 10-18); Psychopathy (items 19-27). 


\section{Moral Intuition Survey}

Directions: Please rate the following statements following the scale below. You can be honest because your name will not be attached to the answers.

\begin{tabular}{ccccc}
\hline Morally & Morally bad & Morally neutral & Morally good & Morally \\
Wrong & but not forbidden & (neither good nor bad) & but not required & Required \\
1 & 2 & 3 & 4 & 5 \\
\hline
\end{tabular}

1. A government ought to tax its citizens in order to ensure that all citizens enjoy basic life necessities (example: Social Security, which provides old-age/retirement benefits, and temporary assistance for needy families, such as food stamps etc.).

2. A government ought to tax its citizens in order to provide financial aid (i.e. "welfare") to the poor and unemployed.

3. A government ought to tax its citizens in order to bring about a more equal or "fair" distribution of wealth.

4. A government ought to restrict citizens' liberties somewhat in order to protect them from terrorist attacks.

5. A government ought to detain suspected terrorists as long as necessary, without trial, in order to prevent terrorist attacks.

6. The government has a duty to conform to United Nations resolutions.

7. The government has the right to wage war on enemy states even if doing so violates United Nations resolutions.

8. A government ought to never intervene in free economic markets except to prevent or punish force (theft, murder) or fraud (breaking contracts).

9. Homosexual behavior is:

10. Gay marriage is:

11. Affirmative Action is:

12. Gun control is:

13. Selfishness is:

14. The death penalty for persons convicted of premeditated murder is:

15. Someone you know asks you an important question that you cannot avoid answering. If you tell the truth, it will cause a number of people significant unhappiness. If you lie, no one will ever find out, and everyone will be happy. Telling the lie is:

16. A trolley is running out of control down a track. If it continues on its current path, it will run over and kill five innocent people. If you flip a switch, the trolley will run down a different track, killing only one innocent person. Flipping the switch is:

17. A trolley is running out of control down a track. If it continues on its current path, it will run over and kill five innocent people. You are on a bridge above the trolley, and there is a very fat man next to you, who you could push in front of the trolley saving the five people. However, the fat man will die. Pushing the fat man is: 


\section{Demographic Information Survey}

1. My age is: [fill in the blank].

2. My gender is: [select from: male, female, transgendered (identify male), transgendered (identify female).

3. My marital status is: [select from: single, permanently partnered, married, divorced, widowed].

4. My highest level of formal education is: [select from: non-high-school graduate, high-school graduate, some undergraduate education, undergraduate degree completed, some graduate education (i.e. some Masters or PhD work), completed Masters (fill in area of study), completed $\mathrm{PhD}$ (fill in area of study).

5. My political party affiliation is best described as (United States citizens only): [select from the following: Democrat, Republican, Independent, Tea Party].

6. I consider myself to be a: [select from scale 1-7, where 1=fiscal/economic conservative, $4=$ fiscal/economic moderate, $7=$ fiscal/economic liberal $]$.

7. I consider myself to be a: [select from scale 1-7, where 1=social conservative, $4=$ social moderate, $7=$ social liberal].

8. I consider myself to be: [select from scale $1-7$, where $1=$ very religious, $4=$ uncommitted/neither religious nor anti-religious, $7=$ anti-religious/atheist].

9. Ethnicity: [select from: Black, Latino, Chinese, Filipino, Indian (far east), Japanese, Korean, Caucasian/white, Native American, Pacific Islander, other Asian, Other (if Other, fill in the blank)].

10. Select your country of residence: [fill in the blank].

11. I have taken how many philosophy classes: [select from: one to five, completed undergraduate philosophy major, completed Masters in Philosophy, completed Phd/DPhil in Philosophy]. 